\title{
Surgical management of coarctation of aorta with ventricular septal defect
}

\section{Multivariate analysis}

\author{
RANJIT LEANAGE^, JAMES F N TAYLOR, MARC R DE LEVAL \\ JAROSLAV STARK, FERGUS J MACARTNEY†
}

From the Department of Paediatric Cardiology and Thoracic Unit, The Hospital for Sick Children, Great Ormond Street, London

SUMmary Optimal management of coarctation with ventricular septal defect is difficult. Should one treat the coarctation, the ventricular septal defect, or both? This dilemma was investigated by reviewing 39 successive patients, aged less than 4 months, undergoing coarctation repair without pulmonary artery banding. Twelve hospital deaths occurred. Ventricular septal defect size was graded "blind" according to preoperative angiocardiographic and haemodynamic findings. Of 14 patients classified as having a large ventricular septal defect, necropsy and operative findings in eight showed defects 7 to $12 \mathrm{~mm}$ in diameter.

Factors associated univariately. with significantly increased mortality were young age, raised atrial and ventricular end-diastolic pressures, low weight, high admission blood urea, preoperative ventilation, and a large ventricular septal defect. All but the last two were also closely associated with each other.

A jack-knifed discriminant function based upon ventricular septal defect size, blood urea, pulmonary venous oxygen content, and inferior caval oxygen saturation correctly predicted outcome in $78.9 \%$ of patients. Combinations of these four giving a probability $>0.9$ of survival were rare with blood ureas above $8 \mathrm{mmol} /$ litre. Raised blood urea was associated with low descending aortic pressure and subsequent dialysis.

Only patients with a large ventricular septal defect stand to benefit from pulmonary artery banding at initial operation. Preoperative treatment to increase renal blood flow (prostaglandins, dopamine) may improve overall survival.

Coarctation of the aorta with ventricular septal defect presents a difficult problem in management when patients present in early infancy in severe heart failure. The need to relieve the coarctation surgically is widely accepted, even though some success has been reported with closure of the defect alone, provided that the coarctation is "moderate". 1 But how should the ventricular septal defect be managed? Some authors maintain that "any child with a large intracardiac left-to-right shunt whose ventricular pressures are equal should undergo coincident (pulmonary artery) banding",2; others advocate

^ RL was awarded a British Heart Foundation Junior Research Fellowship to carry out this study, which was also supported by a British Heart Foundation grant.

† FJM is supported by the Vandervell and British Heart Foundations. Received for publication 14 April 1981 closure of the ventricular septal defect at the same time as relief of the coarctation. ${ }^{3}$ It is known, however, that if the patient survives relief of the coarctation alone, there is a fair chance that the ventricular septal defect will never require closure, or may even close spontaneously. ${ }^{45}$ In other words, routine banding or ventricular septal defect closure may be an unnecessarily aggressive approach.

The poor results of coarctation resection with pulmonary artery banding in earlier years ${ }^{67}$ led us in 1970 to adopt a policy of relieving only the coarctation in the first instance, and, if necessary, closing the ventricular septal defect later with the same indications as for any isolated ventricular septal defect. But this policy could be challenged if it could be shown that some patients were dying in the immediate period after relief of coarctation because 
their ventricular septal defect was too large and had not been dealt with.

It is relatively simple to assess the size of an isolated ventricular septal defect in infancy on the basis of the size of the left-to-right shunt and the degree of pulmonary hypertension. The presence of an associated coarctation, however, makes this more difficult. Infants tend to present much earlier, at a time when pulmonary vascular resistance has, at least in theory, fallen very little from its birth level (this phenomenon also may cause problems in achieving adequate banding). Whether this theory is correct or not, young infants with isolated coarctation of the aorta frequently present with either severe pulmonary hypertension, ${ }^{89}$ a left-to-right shunt at atrial level through a stretched foramen ovale, ${ }^{8}$ or both. It is, therefore, difficult to determine the respective roles played by the ventricular septal defect and the coarctation in determining the size of the left-to-right shunt and the degree of pulmonary hypertension, especially where tricuspid regurgitation is secondary to right ventricular failure, or mitral regurgitation is also present.

This study was therefore carried out to determine the risk factors that were associated with relief of coarctation without banding for ventricular septal defect, and whether a group of patients could be identified who were at special risk on account of the size of the ventricular septal defect.

\section{Subjects and methods}

Between 1 January 1972 and 1 February 1980, 41 patients under 4 months of age with coarctation and ventricular septal defect, but without mitral stenosis or severe left ventricular hypoplasia, had their coarctation relieved. Several patients had associated mitral regurgitation at the time of the study but, as it was not always known whether this was the result of a mitral abnormality or left ventricular failure, these patients were included. Two of these also had banding of the pulmonary artery and have therefore been excluded from the study. No patient was refused operation because they were too sick, and no patient died before reaching the operating theatre. Most patients had had adequate treatment with digoxin and diuretics before referral, and only when this had not occurred was a 48-hour period of intensive medical treatment tried before surgery was undertaken.

The preoperative haemodynamic data, biplane cineangiocardiograms, and operation notes were reviewed and patients counted as dying if they died in hospital before discharge or closure of ventricular septal defect.

Raw rather than derived data were coded and punched onto cards, and the necessary calculations made by a Fortran program run on a Control Data Corporation 6600 computer at the University of London Computing Centre.

Because of the frequency of left-to-right shunts at atrial level, mixed venous oxygen saturation was calculated as $(3 \times$ SVC + IVC) +4 , where SVC is the superior vena caval, and IVC the inferior vena caval oxygen saturation (\%). Pulmonary venous, and pulmonary and systemic arterial saturations were normally taken as a mean of two or three samples. But when the mean left artrial pressure was at least 2 $\mathrm{mmHg}$ higher than right atrial pressure left atrial saturation was taken as the mean pulmonary venous saturation. When calculating oxygen content, 0.3 $\mathrm{ml} / 100 \mathrm{ml}$ per $100 \mathrm{mmHg}$ partial pressure of oxygen was added as oxygen dissolved in the plasma to haemoglobin bound oxygen. The left-to-right shunt was expressed as the percentage of pulmonary arterial blood derived from pulmonary venous blood. This calculation, unlike that of pulmonary/systemic flow ratio, does not depend on knowledge of mixed systemic arterial saturation (in the presence of a coarctation and its associated ductus, it cannot be assumed that ascending and descending aortic saturations are equal).

The angiocardiograms were reviewed by one observer (FJM) not aware of the anatomical findings or fate of the patient. Measurements of the diameter of the ascending aorta, isthmus, and descending aorta were made at the points defined by Sinha and colleagues ${ }^{9}$, the only difference in methodology being that, in seven instances, measurements were made from a left anterior oblique projection associated in five cases with craniocaudal tilt. Because of differences in magnification factor, the diameter of the isthmus was expressed as a ratio of its diameter to that of the ascending and descending aorta, respectively.

Assessment of the size of the ventricular septal defect by angiocardiography was made difficult by the prevalence of frontal and lateral projections in the early years of the study. From the 38 angiocardiograms available (one patient had none), the size of the ventricular septal defect was assessed from a lateral projection in 21 , and a left anterior oblique in 17 , in six of which craniocaudal tilt was added. The septum was always profiled in oblique projections, and was also profiled (because of right ventricular enlargement) in 11 lateral projections. Thus it was possible to measure the ratio between the width of the ventricular septal defect and the length of the left ventricular cavity (apex to aortic valve adjacent to septum) in 28 patients. In the case of multiple defects the sum of the widths was used to calculate what will be termed the ventricular septal ratio.

After studying the relation between ventricular septal ratio and (a) left-to-right shunt and (b) the ratio 
between right and left ventricular systolic pressures, the following algorithm was then applied to categorising ventricular septal defect size.

If the ventricular septal ratio was known, the defect was classified as small for a ratio $<0.125$, large for a ratio $>0 \cdot 25$, and medium otherwise. If the ventricular septal ratio was not known, the defect was initially categorised as small if a jet was seen entering the right from the left ventricle, medium if there was no jet but obvious dilution of contrast medium in the right ventricle, and large if there was dense opacification of the right ventricle. This classification was then overridden if the right ventricular systolic pressure was less than $80 \%$ of the left ventricular systolic pressure. If this was true and the left-to-right shunt was less than $35 \%$, the defect was classified as small; if between $35 \%$ and $55 \%$, the defect was classified as medium. The categorisation was then normalised according to the transformation suggested by Mosteller and Tukey. ${ }^{10}$

The site and number of ventricular septal defects were also observed from the angiocardiogram, as well as the relation of the coarctation to the ductus.

The output from this Fortran program was then put onto disc and read into the Statistical package for the social sciences ${ }^{11}$ for cross-tabulation, unpaired two-tailed $\mathrm{t}$ tests, bivariate regression, and stepwise discriminant function analysis, predicting death or survival. Transformations were carried out where necessary to normalise data and remove statistically significant difference in variance before performing Student's $t$ test. The test for trend in discontinuous variables employed was that advocated by Snedecor and Cochran. ${ }^{12}$

The precise method of use of stepwise discriminant function is as previously described, ${ }^{13}$ except that ventricular septal defect size was forced into the analysis, so that the effect of other factors, given that size, could be assessed. After deciding on the most valuable discriminant function, a data set containing no missing values for any of the predictive variables was then tested for its discriminating capacity on an unknown population by jack-knifing, using the Genstat $^{14}$ macro routine on the CDC 7600 computer at the University of London Computing Centre.

Finally, a set of imaginary patients was created by forming combinations of the different factors in the discriminant function and calculating probabilities of survival for individuals by the Bayesian method available in the Statistical package for the social sciences.

\section{Results}

PROFILE OF POPULATION

These patients were ill at the start of cardiac catheterisation. Their ages ranged from 2 to 109 days (median 19.3 days) ${ }^{\star}$ and $44 \%$ were 2 weeks old or younger. The weights ranged from $2 \cdot 2$ to $4.8 \mathrm{~kg}$ (mean $3 \cdot 3 \pm$ SD $0 \cdot 68$ ). The left ventricular enddiastolic pressure ranged from 4 to $35 \mathrm{mmHg}$ (mean $15 \mathrm{mmHg}$ ) and $39 \%$ of patients had a right atrial mean pressure above $10 \mathrm{mmHg}$. The initial base excess varied from $-21 \mathrm{mEq} / 1$ to $+14 \mathrm{mEq} / 1$ (median $-4 \cdot 6$ ). Systemic arterial $\mathrm{pH}$ ranged from $7 \cdot 12$ to $7 \cdot 62$ (median 7-36). Eleven patients required ventilation even before the cardiac catheterisation because of their critical condition. The blood urea varied from 2.4 to 20.0 (median 7.1 ) $\mathrm{mmol} /$ litre. In one patient, peritoneal dialysis was begun for acute renal failure even before cardiac catheterisation. At that time, no patients received prostaglandins to maintain duct patency, which was always present.

The site and type of ventricular septal defect was impossible to ascertain preoperatively in four patients. Of the remaining 35 patients, nine $(23 \cdot 1 \%)$ were judged to have multiple defects, $15(38.5 \%)$ a single perimembranous defect, eight $(20.5 \%)$ a single trabecular (muscular) defect, two $(5 \cdot 7 \%)$ a single high defect (unspecified), and one $(2 \cdot 8 \%)$ a single infundibular subarterial defect. The mean left-toright shunt was $63 \cdot 8 \%$ ( \pm SD $22 \cdot 9$ ).

In every case, the ductus arteriosus and descending aorta formed a smooth continuous curve. The posterior wall of the isthmus, instead of continuing smoothly into the posterior wall of the descending aorta; turned forward to insert into it at an angle, that angle being the coarctation. The ratio between the diameters of isthmus and aorta could be assessed in all but three cases. Isthmus/ascending aorta ratio ranged from 0.17 to 0.64 (mean $0.431 \pm$ SD 0.103 ) and isthmus/descending aorta ratio from 0.33 to 1.0 (mean $0.599 \pm S D 0 \cdot 16$ ). The systolic gradient across the coarctation (ascending to descending aorta) ranged from 0 (in a patient with a large persistent ductus with a right-to-left shunt through it) to $80 \mathrm{mmHg}$ (mean 38.1 \pm SD 19.5), but was unknown in 15. The maximum systolic gradient between left ventricle and ascending aorta was $30 \mathrm{mmHg}$. The coarctation was repaired by resection in 24 patients and by subclavian flap repair ${ }^{15} 16$ in 15 . The latter operation has been the procedure of choice since late 1977.

CAUSES OF DEATH AND FACTORS PREDICTIVE OF DEATH

Twelve patients died $(30.8 \%)$, three on the operating table (one with the chest open but before resection of the coarctation), three of renal failure, one of septicaemia, one of peritonitis secondary to peritoneal dialysis, one of bilateral intraventricular haemor-

* Medians are quoted rather than means for very skew distributions. 
rhage, one of subdural haemorrhage, one of bronchopneumonia resulting from recurrence of a tracheooesphageal fistula repaired at another hospital, and one of uncertain causes.

Table 1 lists those factors where there was a statistically significant $(\mathrm{p}<0.05)$ difference in mean values of the predictor before and after survival. These, on univariate analysis, are age, left ventricular end-diastolic pressure, right atrial mean pressure, weight, and blood urea.

Table 2 lists those factors in which no statistically significant association with survival was shown on univariate analysis. Inferior vena caval saturation

Table 1 Factors in which a significant difference in mean values was found between patients surviving and dying

\begin{tabular}{|c|c|c|c|c|c|}
\hline Factor & $\begin{array}{l}\text { Mean } \pm S E \\
\text { in survivors }\end{array}$ & $\begin{array}{l}\text { No. of } \\
\text { survivors }\end{array}$ & $\begin{array}{l}\text { Mean } \pm S E \\
\text { of non- } \\
\text { survivors }\end{array}$ & $\begin{array}{l}\text { No. of } \\
\text { non- } \\
\text { survivors } 1\end{array}$ & Probability \\
\hline $\begin{array}{c}\log _{10} \text { age } \\
\text { (days) } \\
\text { LVEDP }\end{array}$ & $1 \cdot 37 \pm 0.08$ & 27 & $0.92 \pm 0.12$ & 12 & $\mathrm{p}<0.005$ \\
\hline $\begin{array}{l}(\mathrm{mmHg}) \\
\text { RAMP }\end{array}$ & $13 \cdot 3 \pm 1 \cdot 3$ & 27 & $19 \cdot 7 \pm 2 \cdot 3$ & 10 & $\mathrm{p}<0.02$ \\
\hline $\begin{array}{l}(\mathbf{m m H g}) \\
\text { Weight }\end{array}$ & $6.6 \pm 0.9$ & 27 & $11 \cdot 1 \pm 1 \cdot 9$ & 12 & $\mathrm{p}<0.02$ \\
\hline $\begin{array}{c}(\mathrm{kg}) \\
\text { Blood }\end{array}$ & $3 \cdot 5 \pm 0.13$ & 27 & $2 \cdot 9 \pm 0 \cdot 16$ & 12 & $p<0.01$ \\
\hline $\begin{array}{l}\text { Dlood urea } \\
(\mathrm{mmol} / \mathrm{l})\end{array}$ & $6.4 \pm 0.7$ & 27 & $10 \cdot 7 \pm 1 \cdot 3$ & 12 & $p<0.005$ \\
\hline
\end{tabular}

LVEDP, left ventricular end-diastolic pressure; RAMP, right atrial mean pressure.

Table 2 Continuous variables for which no significant difference in mean values was found between patients surviving and dying

\begin{tabular}{ll}
\hline Factor & Population base \\
\hline Pulmonary venous oxygen saturation and content & 38 \\
Systemic venous oxygen saturation and content & 38 \\
Pulmonary arterial oxygen saturation and content & 36 \\
Descending aortic oxygen saturation and content & 28 \\
Left atrial mean pressure & 39 \\
Pulmonary arterial mean pressure & 36 \\
Right ventricular systolic pressure & 39 \\
Left ventricular systolic pressure & 39 \\
Pulmonary artery systolic pressure & 38 \\
Ascending aortic systolic pressure & 30 \\
Descending aortic systolic pressure & 27 \\
Systemic arterial or left ventricular pH & 37 \\
Systemic arterial or left ventricular base excess & 37 \\
Blood haemoglobin concentration & 38 \\
Left-to-right shunt & 38 \\
Ventricular septal ratio & 28 \\
Isthmal to ascending aorta ratio & 36 \\
Isthmal to descending aorta ratio & 36 \\
Systolic pressure gradient across aortic valve & 39 \\
Systolic pressure gradient across coarctation & 24 \\
Systolic pressure ratio (right/left ventricle) & 37 \\
\hline
\end{tabular}

tended to be higher in those who died, but this difference was not statistically significant.

Tables 3 to 5 list discontinuous factors significantly associated with death or survival. These are dialysis (in each case peritoneal) after operation, mechanical ventilation before cardiac catheterisation, and the size of the ventricular septal defect. There was no association with the site or number of ventricular septal defects, the method of repair of coarctation, or the year of surgical repair.

\section{INTERACTION BETWEEN DIFFERENT FACTORS}

There was a significant positive correlation between the ratio between the right and left ventricular systolic pressure ratios and the ventricular septal ratio $(r=0.43, p<0.05)$ (Fig. 1), though there was no correlation between the latter and the left-to-right shunt $(r=0.06, n=27)$. This lack of correlation was, however, the result of a single patient with a septal ratio of 0.58 , measured from the lateral angiocardiogram, and a shunt of $38 \%$. The shunt was positively correlated with the left ventricular enddiastolic pressure $(r=0.38, \mathrm{p}<0.02)$ (Fig. 2).

Table 3 Relation between postoperative peritoneal dialysis and survival

\begin{tabular}{llll}
\hline & No dialysis & Dialysis & Total \\
\hline Survived & 26 & 1 & 27 \\
Died & $5(16 \cdot 1 \%)$ & $7(72 \cdot 7 \%)$ & $12(30 \cdot 8 \%)$ \\
Total & 31 & 8 & 39 \\
\hline
\end{tabular}

$\chi^{2}(1$ degree of freedom $)=12.04 \mathrm{p}<0.001$.

Table 4 Relation between artificial ventilation at time of catheterisation and survival

\begin{tabular}{llll}
\hline & No ventilation & Ventilation & Total \\
\hline Survived & 24 & 3 & 27 \\
Died & $4(14 \cdot 3 \%)$ & $8(72 \cdot 7 \%)$ & $12(30 \cdot 8 \%)$ \\
Total & 28 & 11 & 39 \\
\hline
\end{tabular}

$\chi^{2}(1$ degree of freedom $)=10.07 \mathrm{p}<0.002$.

Table 5 Relation between size of ventricular septal defect and survival

\begin{tabular}{|c|c|c|c|c|}
\hline & $\begin{array}{l}\text { Ventricular } \\
\text { Small }\end{array}$ & $\begin{array}{l}\text { ptal defect } \\
\text { Medium }\end{array}$ & Large & Total \\
\hline $\begin{array}{l}\text { Alive } \\
\text { Dead } \\
\text { Total }\end{array}$ & $\begin{array}{l}13 \\
2(13 \cdot 3 \%) \\
15\end{array}$ & $\begin{array}{l}7 \\
2(22 \cdot 2 \%) \\
9\end{array}$ & $\begin{array}{l}7 \\
7(50 \%) \\
14\end{array}$ & $\begin{array}{l}27 \\
11(28 \cdot 9 \%) \\
38^{\star}\end{array}$ \\
\hline
\end{tabular}

Test for trend $Z=2.12 p<0.05$.

* Ventricular septal defect size could not be assessed in one patient. 


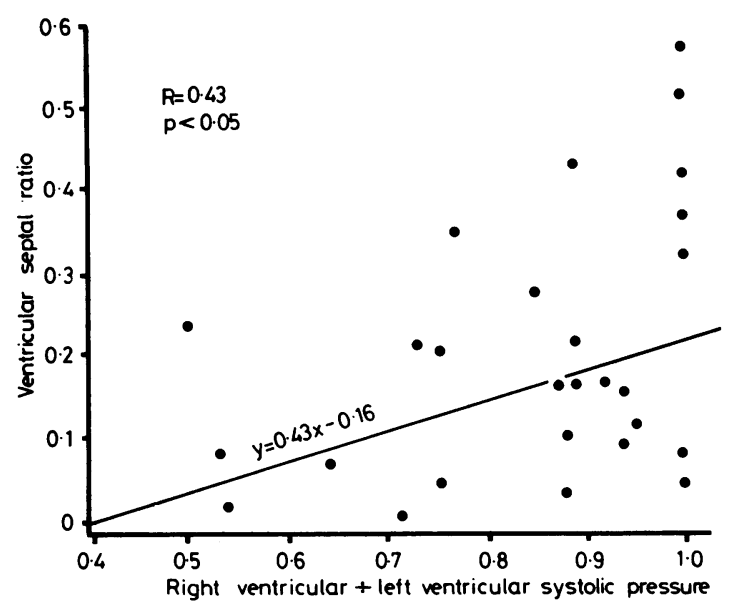

Fig. 1 Relation between ventricular septal ratio and ratio between ventricular systolic pressures.

There was no correlation between age, shunt, or ventricular systolic pressure with the degree of isthmal hypoplasia as assessed by the ratios of diameters of isthmus and ascending or descending aorta.

There was a weak positive correlation $(r=0.39$, $p<0.02$ ) between $\log _{10}$ age and base excess, and a strong negative correlation between $\log _{10}$ age and right atrial mean pressure $(\mathrm{r}=-0.68, \mathrm{p}<0.00002)$, left atrial mean pressure $(r=-0.55, p<0.0005)$ (Fig. 3), left ventricular end-diastolic pressure $(r=$ $-0.62, \mathrm{p}<0.00005)$, and blood urea $(\mathrm{r}=-0.44, \mathrm{p}<$ $0.01)$. The correlation between $\log _{10}$ age and shunt was negative, but not statistically significant.

Patients who ultimately underwent dialysis had a significantly $(p<0.005)$ higher admission blood urea (mean 11.7 \pm SE $1.6 \mathrm{mmol} / \mathrm{l}$ ) than did those who did not (mean $6.7 \pm \mathrm{SE} 0.7 \mathrm{mmol} / \mathrm{l}$ ). There was a

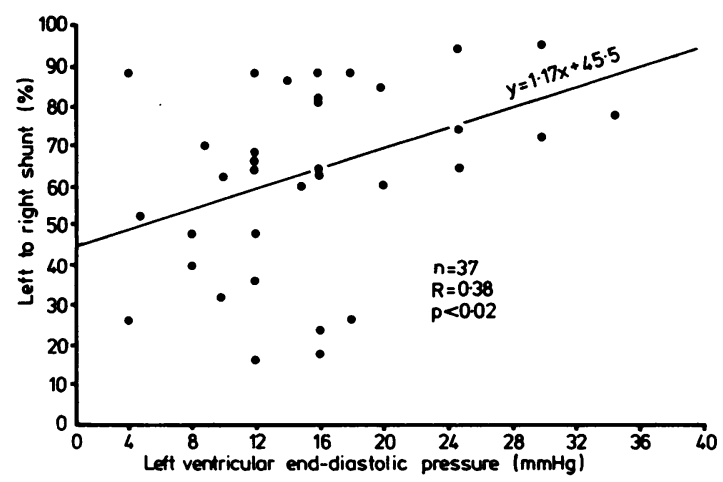

Fig. 2 Relation between left-to-right shunt and left ventricular end-diastolic pressure.

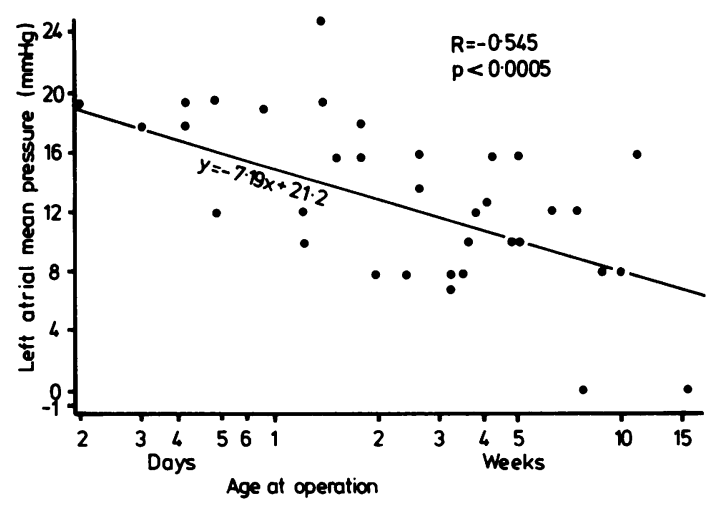

Fig. 3 Relation between age and left atrial mean pressure.

significant positive correlation between blood urea and left atrial mean pressure $(r=0.37, p<0.05)$ and right atrial mean pressure $(r=0.35, p<0.05)$. There was a strong tendency for high blood ureas to be associated with low descending aortic systolic pressures (Fig. 4), though the statistical significance of this relation was vitiated by two patients in whom the ductus was probably labile.

\section{MULTIVARIATE PREDICTION OF DEATH}

This was based on continuous variables, the single exception being the size of the ventricular septal defect, which was coded (according to the normalising transformation) -1.7 for small, 0.05 for medium, and 0.7 for large defects. The simplest and most accurate prediction was based upon the size of the ventricular septal defect, the inferior vena caval saturation, the

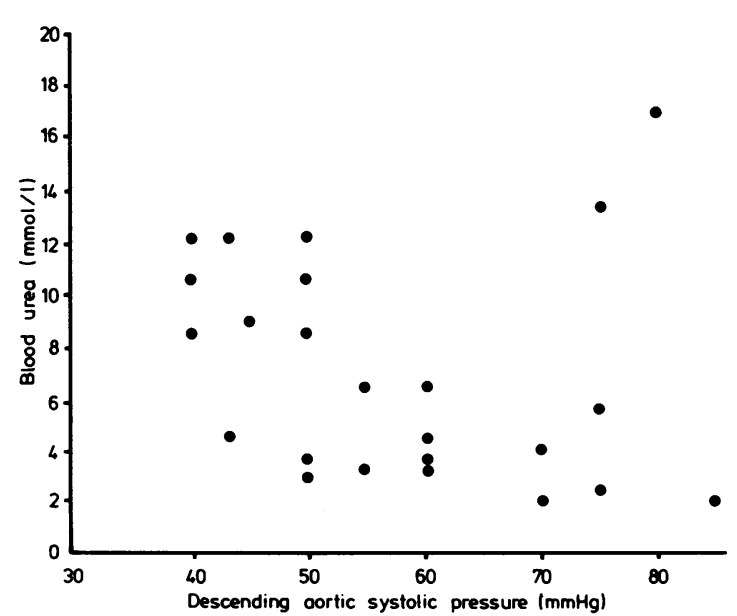

Fig. 4 Relation between blood urea and descending aortic systolic pressure. 
pulmonary venous oxygen content, and blood urea concentration. Details of the discriminant function are shown in Table 6, and the performance of the jack-knifed function in Table 7. Fig. 5 gives the probability of survival for different combinations of predictors.

\section{OUTCOME ACCORDING TO SIZE OF}

VENTRICULAR SEPTAL DEFECT, AND ACCURACY OF LATTER ASSESSMENT

This is summarised in Fig. 6. In one patient there had in retrospect been a gross misreading of lateral angiocardiogram. Confusion of a narrow initial jet with subsequent opacification of the whole width of the ventricular septal defect led to classification of the ventricular septal defect as small, when it in fact turned out to be $12 \times 14 \mathrm{~mm}$ at surgical closure two years later.

Apart from that, if a defect was classified as large, it was found to be at least $5 \mathrm{~mm}$ in diameter at necropsy or operation soon afterwards. If the defect was classified as medium or small, the maximum diameter was $3 \mathrm{~mm}$ at the same time, though in one patient classified as having a medium size defect the infundibular defect found at operation was probably slightly larger, but was not measured. In 38 of the patients in whom ventricular septal defect size could be assessed preoperatively, six (15.8\%) spontaneous closures of the defect occurred, documented by left ventricular angiocardiography in three. In a further 16 patients $(42 \cdot 1 \%)$ the defect during follow-up was or became sufficiently small not to require further operation. By this we mean that in the six patients catheterised after repair of coarctation there were normal right sided pressures and a pulmonary/ systemic flow ratio less than 2:1. The clinical diagnosis of a small defect rested on a pansystolic or early systolic murmur at the lower left sternal border with a normal second heart sound and no diastolic murmur, absence of right ventricular hypertrophy on the electrocardiogram, and at most minimal cardio-

Table 6 Summary of stepwise discriminant analysis

\begin{tabular}{llcl}
\hline $\begin{array}{l}\text { Step } \\
\text { number }\end{array}$ & $\begin{array}{l}\text { Variable } \\
\text { entered }\end{array}$ & $\begin{array}{l}\text { F to } \\
\text { enter }\end{array}$ & $\begin{array}{l}\text { Wilks' } \\
\text { Lambda }\end{array}$ \\
\hline 1 & VSDSIZ & 3.91 & 0.800 \\
2 & UREA & 6.05 & 0.764 \\
3 & IVC & 6.24 & 0.642 \\
4 & PVCONT & $10 \cdot 10$ & 0.488 \\
\hline
\end{tabular}

Survival is predicted if: $0.223 \times$ UREA $-0.229 \times$

PVCONT + 0.0839 $\times$ IVC + 0.177 $\times$ VSDSIZ < 4.31.

IVC, inferior vena caval oxygen saturation (\%);

PVCONT, pulmonary venous oxygen content $(\mathrm{ml} / 100 \mathrm{ml})$;

UREA, blood urea (mmol/);

VSDSIZ, size of ventricular septal defect (coded as in text).
Table 7 Performance of jack-knifed discriminant function, based on blood urea, ventricular septal defect size, pulmonary venous oxygen content, and inferior vena caval saturation

\begin{tabular}{llccl}
\hline & \multicolumn{4}{c}{ Predicted state } \\
& & Alive & Dead & Total \\
\hline \multirow{4}{*}{ Actual state } & Alive & 21 & 6 & 27 \\
& Dead & 2 & 8 & 10 \\
& Total & 23 & 14 & 37 \\
\hline
\end{tabular}

Correct prediction in $\mathbf{7 8 . 4 \%}$ of cases.

megaly on chest radiography, and/or left ventricular hypertrophy by electrocardiography. Thus, over half the patients will never require surgical treatment of the ventricular septal defect, other than for bacterial endocarditis or aortic regurgitation, neither of which have yet occurred.

\section{Discussion}

In 1979 , Fleming and colleagues ${ }^{17}$ reported a remarkable series of patients under 3 months of age operated for coarctation with ventricular septal defect. Pulmonary artery banding was carried out after patch aortoplasty of the coarctation if the pulmonary artery systolic pressure was greater than two-thirds aortic systolic pressure. No deaths occurred in 13 patients.

With this notable exception, our overall results differ little from those reported over the past 10 years by others ${ }^{1} 4^{18-23}$ whether or not pulmonary artery

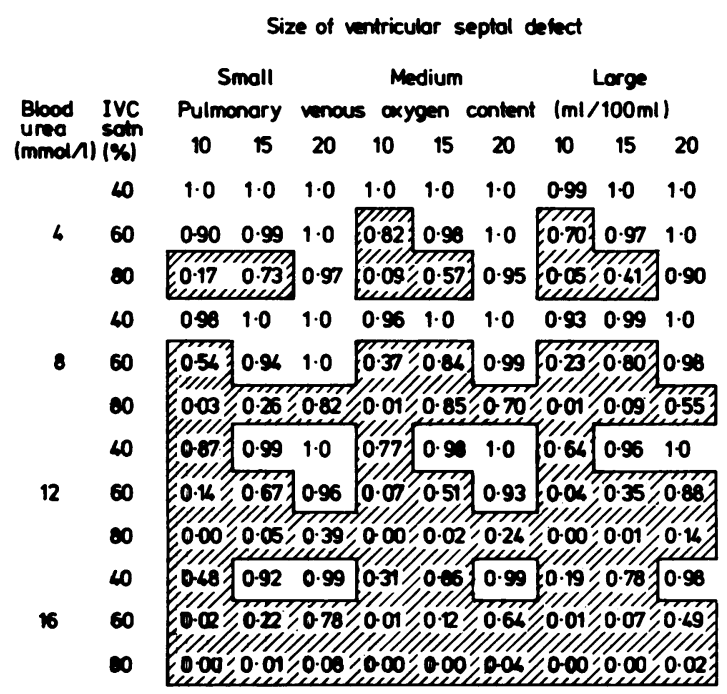

Shoded oreas represent probability $<0.9$ of survival

Fig. 5 Probability of survival given different "risk factors". 


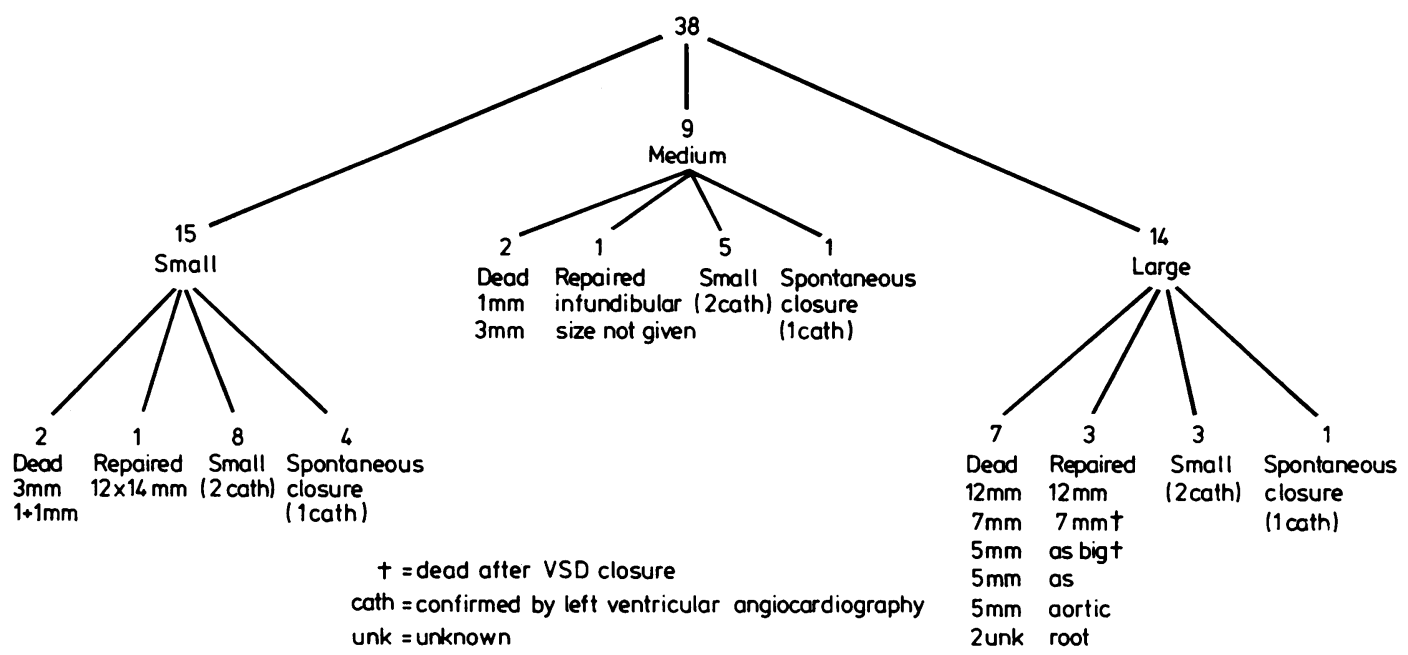

Fig. 6 Fate according to size of ventricular septal defect.

banding was carried out. Coarctation repair and ventricular septal defect repair at the same time was successfully carried out in both of two patients under 4 months of age reported by Tiraboschi and colleagues, ${ }^{3}$ and in one of two patients reported by Barratt-Boyes and colleagues. ${ }^{1}$

The group as a whole had a strong tendency towards intractable heart failure, raised atrial and left ventricular end-diastolic pressures, metabolic acidosis, and increase in blood urea, particularly in the youngest patients. What is it that makes them so sick? To answer this question, it is helpful to consider coarctation without ventricular septal defect first.

The idea that partial or complete constriction of the ductus arteriosus initiates the problem is not new. ${ }^{24}$ Experimental and clinical observations to support this theory are, however, now available. ${ }^{25-27}$ The ensuing consequences of biventricular failure, atrial left-toright shunting, depressed renal blood flow, and fluid retention have been admirably discussed by Graham and colleagues, ${ }^{8}$ and supported by evidence in patients in the first two weeks of life of depression in left and right ventricular ejection fraction and reduction in left ventricular but increase in right ventricular stroke output. The effect of increased afterload on the left ventricle could be explained either on the basis of the diminished myocardial force generating capacity per unit area of neonatal myocardium 2829 or the presence of widespread myocardial ischaemia. ${ }^{30}$ The fact that older infants, however, appear to be able to compensate for the afterload better, ${ }^{8}$ and that the long term prognosis for survivors is so good ${ }^{31}$ argue somewhat in favour of the first hypothesis.
Addition of a ventricular septal defect compounds the above problems by producing left ventricular volume overload, and making the pulmonary hypertension and therefore right ventricular pressure overload more likely.

The first organs, other than the heart, to suffer from this onslaught appear to be the kidneys, yet we were unable to find a report on surgical management of coarctation in infancy which documented renal performance preoperatively apart from a single case report of a patient with coarctation and aortic stenosis in whom relief of the coarctation dramatically reduced preoperative azotaemia. ${ }^{32}$ While the blood urea has its limitations as a measure of renal function it was, in our experience, an effective predictor both of surgical outcome and of the need for dialysis. Furthermore, it supplanted both age and weight on prediction of outcome by multivariate analysis, thereby supporting the previous contention ${ }^{6}$ that age per se is not a risk factor. With the size of the ventricular septal defect and the blood urea allowed for, pulmonary venous oxygen content and inferior vena caval oxygen saturation appeared as risk factors when they had not done so on univariate analysis. It is not difficult to see why pulmonary venous desaturation and a low haemoglobin concentration were associated with a worse prognosis. We interpret the fact that a low inferior vena caval oxygen saturation was a good prognostic sign as meaning that these patients had a wide arteriovenous oxygen difference across the lower half of the body and therefore a poor lower body systemic flow. They therefore stood to gain most from resection of the coarctation, given that their renal function was not already severely compromised. 
Inspection of Fig. 5 shows that when preoperative blood urea is $12 \mathrm{mmol} /$ litre or above (as it was in eight of the patients) the probability of survival is greater than $90 \%$ only in exceptional circumstances. Furthermore, our results show that in the majority of patients the lower the descending aortic systolic pressure, the higher the blood urea. Though one cannot be sure that altering a factor predicting poor survival will improve survival, this does suggest that use of prostaglandins preoperatively could improve overall outcome in patients with raised admission blood urea. Heymann and colleagues ${ }^{33}$ have documented an increase in descending aortic pressure on infusion of prostaglandin $E_{1}$ in patients with juxtaductal coarctation. Though no measure of renal function was made, it was noted that all infants passed urine after prostaglandin infusion, though, in most instances, they had not voided for several hours previously. These authors took the view that reopening the ductus arteriosus had enabled ascending aortic blood to bypass the juxtaductal coarctation. It will be noted that our angiocardiographic description of the coarctation present in our patients is that of a preductal coarctation, which was also the operative diagnosis in most instances. We doubt whether this is of any great importance for two reasons. First, distinction between the two entities is so subtle that we have little doubt that the same lesion (that is a discrete coarctation with greater or less degrees of isthmal hypoplasia) is being described. Second, the clear demonstration in infants that the coarctation actually results from a sling of ductal tissue around the aorta ${ }^{34} 35$ raises the possibility that prostaglandins could act by relaxing the sling and thereby relieving the coarctation. The remarkable angiocardiograms published by Talner and Berman ${ }^{26}$ show a slight posterior shelf existing before closure of the ductus being pulled toward the ductus after ductal closure and forming a severe coarctation. It is difficult to escape the conclusion that longitudinal ductal constriction, including the sling of tissue, has produced this result. This hypothesis would also explain the constriction of the neonatal aorta by raised oxygen tension observed by Gillman and Burton ${ }^{36}$ in several animal species.

Thus, the first line of treatment in patients with evidence of depressed renal function appears to be a trial of prostaglandin together with routine antifailure treatment and transfusion of packed cells if necessary. When the maximum benefit, if any, has been achieved, cardiac catheterisation and angiocardiography can be carried out. Coarctation repair is then performed. The long term fate of small and medium sized ventricular septal defects, as we have defined them, suggests that there is no place in these groups either for pulmonary artery banding or for primary ventricular septal defect closure. Greater use of tilted oblique views of the interventricular septum should enable more accurate identification of large defects, and, in our experience, make visualisation of the coarctation if anything easier than standard frontal and lateral projections. Though one-stage coarctation repair and ventricular septal defect closure is an attractive idea, no successful series of any size in these very young infants has yet been reported. In those patients who, after preliminary medical treatment as outlined above, still have a less than $90 \%$ chance of surviving coarctation resection alone, our preference would be for pulmonary artery banding at the time of coarctation resection, with debanding and ventricular septal defect closure at 6 to 12 twelve months of age, hopefully before any undesirable complications of banding have ensued. Only in cases where ventricular septal defect closure would necessitate a left ventriculotomy would we postpone secondary repair until the second or third year of life.

\section{References}

1 Barratt-Boyes BG, Neutze JM, Clarkson PM, Shardley GC, Brandt PWT. Repair of ventricular septal defect in the first two years of life using profound hypothermiacirculatory arrest techniques. Ann Surg 1976; 184: 376-90.

2 Connors JP, Hartmann AF Jr, Weldon CS. Considerations in the surgical management of infantile coarctation of aorta. Am $\mathcal{F}$ Cardiol 1975; 36: 489-92.

3 Tiraboschi R, Alfieri O, Carpentier A, Parenzan L. One stage correction of coarctation of the aorta associated with intracardiac defects in infancy. 7 Cardiovasc Surg (Torino) 1978; 19: 11-6.

4 Neches WH, Park SC, Lenox CC, Zuberbuhler JR, Siewers RD, Hardesty RL. Coarctation of the aorta with ventricular septal defect. Circulation 1977; 55: 189-94.

5 Chen SC, Fagan LF, Mudd GJF, Willman VL. Prognosis of infants with coarctation of aorta. Am Heart f 1977; 94: 557-61.

6 Tawes RL Jr, Aberdeen E, Waterston DJ, BonhamCarter RE. Coarctation of the aorta in infants and children. A review of 333 operative cases, including 179 infants. Circulation 1969; 39 \& 40, suppl I: 173-84.

7 Stark J, Aberdeen E, Waterston DJ, Bonham-Carter RE, Tynan M. Pulmonary artery constriction (banding): a report of 146 cases. Surgery 1969; 65: 808-18.

8 Graham TP Jr, Atwood GF, Boerth RC, Boucek RJ Jr, Smith CW. Right and left heart size and function in infants with symptomatic coarctation. Circulation 1977; 56: 641-7.

9 Sinha SN, Kardatzke ML, Cole RB, Muster AJ, Wessel HU, Paul MH. Coarctation of the aorta in infancy. Circulation 1969; 40: 385-98.

10 Mosteller F, Tukey JW. Data analysis and regression. Reading (Massachusetts), Menlo Park (California), London, Amsterdam, Ontario, and Sydney: AddisonWesley, 1977: 106-7. 
11 Nie NH, Hull CH, Jenkins JG, Steinbrenner K, Bent DH. Statistical package for the social sciences. 2nd ed. New York: McGraw-Hill, 1975.

12 Snedecor GW, Cochran WG. Statistical methods. 6th ed. Ames, Iowa: The Iowa State University Press, 1967: 246-7.

13 Leanage R, Agnetti A, Graham G, Taylor J, Macartney FJ. Factors influencing survival after balloon atrial septostomy for complete transposition of great arteries. Br Heart F 1981; 45: 559-72.

14 Alvey NG, Banfield CF, Baxter RI, et al. Genstat - a general statistical program. Harpenden, Herts: The Statistics Department, Rothamsted Experimental Station, 1977.

15 Waldhausen JA, Nahrwold DL. Repair of coarctation of the aorta with a subclavian flap. $\mathcal{F}$ Thorac Cardiovasc Surg 1966; 51: 532-3.

16 Hamilton DI, Di Ausanio G, Sandrasagra FA, Donnelly RJ. Early and late results of aortoplasty with a left subclavian flap for coarctation of the aorta in infancy. $\mathcal{F}$ Thorac Cardiovasc Surg 1978; 75: 699-704.

17 Fleming WH, Sarafian LB, Clark EB, et al. Critical aortic coarctation: patch aortoplasty in infants less than age 3 months. Am $\mathcal{F}$ Cardiol 1979; 44: 687-90.

18 Litwin SB, Bernard WF, Rosenthal A, Gross RE. Surgical resection of coarctation of the aorta in infancy. $\mathcal{F}$ Pediatr Surg 1971; 6: 307-13.

19 Fishman NH, Bronstein MH, Berman W Jr, et al. Surgical management of severe aortic coarctation and interrupted aortic arch in neonates. $\mathcal{F}$ Thorac Cardiovasc Surg 1976; 71: 35-48.

20 Chiariello L, Agosti J, Subramanian S. Coarctation of the aorta in children and adolescents. Surgical treatment and review of 120 patients. Chest 1976; 70: 621-6.

21 Shinebourne EA, Tam ASY, Elseed AM, et al. Coarctation of the aorta in infancy and childhood. $\mathrm{Br}$ Heart f 1976; 38: 375-80.

22 Macmanus Q, Starr A, Lambert LE, Grunkemeier G. Correction of aortic coarctation in neonates: mortality and late results. Ann Thorac Surg 1977; 24: 544-9.

23 Midgley FM, Scott LP, Perry LW, Shapiro SR, McClenathan JE. Subclavian flap aortoplasty for treatment of coarctation in early infancy. $\mathcal{F}$ Pediatr Surg 1978; 13: 265-8.

24 Craigie D. Instance of obliteration of the aorta beyond the arch illustrated by similar cases and observations. Edinburgh Medical and Surgical fournal 1841; 56: 42762.
25 Rudolph AM, Heymann MA, Spitznas U. Hemodynamic considerations in the development of narrowing of the aorta. Am $\mathcal{F}$ Cardiol 1972; 30: 514-25.

26 Talner NS, Berman MA. Postnatal development of obstruction in coarctation of the aorta; role of the ductus arteriosus. Pediatrics 1975; 56: 562-9.

27 Elseed AM, Shinebourne EA, Paneth M. Manifestation of juxtaductal coarctation after surgical ligation of persistent ductus arteriosus in infancy. Br Heart $\mathcal{F} 1974$; 36: 687-92.

28 Davies P, Dewar J, Tynan M, Ward R. Post-natal developmental changes in the length-tension relationship of cat papillary muscles. F Physiol (Lond) 1975; 253: 95-102.

29 Friedman WF. The intrinsic physiologic properties of the developing heart. Prog Cardiovasc Dis 1972; 15: 87-111.

30 Tawes RL Jr, Berry CL, Aberdeen E, Graham GR. Myocardial ischemia in infants. Its role in three common congenital cardiac anomalies. Ann Thorac Surg 1969; 8: 383-90.

31 Macartney FJ, Taylor JFN, Graham GR, de Leval M, Stark J. The fate of survivors of cardiac surgery in infancy. Circulation 1980; 62: 80-91.

32 Billig DM, Braver JM, Greenfield JB, Kreidberg MB, Chernoff HL, Khan MAA. Coarctation of the aorta with congestive heart failure and severe azotemia - successful surgical treatment in a neonate. $N$ Engl F Med 1972; 287: 182.

33 Heymann MA, Berman W Jr, Rudolph AM, Whitman V. Dilatation of the ductus arteriosus by prostaglandin $E_{1}$ in aortic arch abnormalities. Circulation 1979; 59: 169-73.

34 Ho SY, Anderson RH. Coarctation, tubular hypoplasia, and the ductus arteriosus. Histological study of 35 specimens. Br Heart $\mathcal{F} 1979 ; 41$ : 268-74.

35 Brom AG. Narrowing of the aortic isthmus and enlargement of the mind. $\mathcal{F}$ Thorac Cardiovasc Surg 1965; 50: $166-80$.

36 Gillman RG, Burton AC. Constriction of the neonatal aorta by raised oxygen tension. Circ Res 1966; 19: 755-65.

Requests for reprints to Professor F J Macartney, The Hospital for Sick Children, Great Ormond Street, London WC1N 3JH. 